\title{
RHINOLOGY
}

\section{Association between upper airway obstruction and malocclusion in mouth-breathing children}

\section{Associazione tra l'ostruzione delle vie aeree superiori e le malocclusioni in bambini con respirazione orale}

\author{
Paola Festa ${ }^{1,2}$, Nicola Mansi ${ }^{1}$, Alfonso Maria Varricchio ${ }^{1}$, Fabio Savoia ${ }^{3}$, Camilla Cali ${ }^{3}$, Carmela Marraudino ${ }^{4}$, \\ Giovanni Carlo De Vincentiis ${ }^{5}$, Angela Galeotti² \\ ${ }^{1}$ Otorhinolaryngology Unit, AORN Santobono-Pausilipon, Naples, Italy; ${ }^{2}$ Dentistry Unit, Bambino Gesù Children's Hospital, IRCCS, Rome, \\ Italy; ${ }^{3}$ Evaluative Epidemiology-Childhood Cancer Registry of Campania, AORN Santobono-Pausilipon, Naples, Italy; ${ }^{4}$ Dentistry Unit, \\ AORN Santobono-Pausilipon, Naples, Italy; ${ }^{5}$ Otorhinolaryngology Unit, Bambino Gesù Children's Hospital, IRCCS, Rome, Italy
}

\begin{abstract}
SUMMARY
Objectives. To evaluate the association between upper airway obstruction and occlusal anomalies in mouth-breathing children.

Methods. 356 mouth-breathing children were evaluated by ENT physicians and specialists in orthodontics. ENT examination included nasal endoscopy to assess the adenoidal hypertrophy, tonsillar grading and presence of nasal septum deviation. Clinical orthodontic examination was performed to record occlusal variables. Univariate and multivariable logistic regression were performed to study the association between registered variables.

Results. 221 patients (mean age $\pm \mathrm{sd}=6.2 \pm 2.5$ years) met inclusion criteria. $81.4 \%$ of children presented malocclusion. A significant association between tonsillar grade 2 and the presence of malocclusion, Class II relation and increased overjet was shown. Tonsillar grade 4 showed a significant association with the presence of malocclusion and increased overjet. Adenoidal hypertrophy and nasal septum deviation did not show any association with occlusal findings.

Conclusions. A high frequency of orthodontic problems was seen in mouth-breathing children. Our results suggested that severe tonsillar hypertrophy may determine presence of malocclusion and increased overjet. On the other hand, the association between mild tonsillar hypertrophy and many occlusal anomalies in mouth-breathers suggest an important role of malocclusion in the onset of oral breathing in children.
\end{abstract}

KEY WORDS: mouth-breathing, malocclusion, adenoids, tonsils, nasal septum deviation

\section{RIASSUNTO}

Razionale. Valutare l'associazione tra l'ostruzione delle vie aeree superiori e le anomalie occlusali in bambini con respirazione orale.

Metodi. 356 pazienti pediatrici con respirazione orale sono stati valutati in un ambulatorio multidisciplinare composto da specialisti in otorinolaringoiatria ed ortognatodonzia. La visita prevedeva valutazione otorinolaringoiatrica con rinofibroscopia e valutazione ortodontica. Risultati. 221 pazienti (età media \pm dev st $=6,2 \pm 2,5$ anni) rispondevano ai criteri di inclusione e sono stati inseriti nel presente studio. L'81,4\% dei pazienti presentava una malocclusione. Un'associazione statisticamente significativa è stata evidenziata tra il $2^{\circ}$ grado di ipertrofia tonsillare e presenza di malocclusione, malocclusione di Classe II e overjet aumentato. L'ipertrofia tonsillare di $4^{\circ}$ grado è risultata associata alla presenza di malocclusione e overjet aumentato. L'ipertrofia adenoidea e la deviazione del setto nasale non sono risultate associate alle variabili occlusali.

Conclusioni. Nei bambini con respirazione orale è presente un'elevata frequenza di anomalie occlusali. I nostri risultati suggeriscono che una grave ipertrofia tonsillare può determinare la presenza di malocclusione e aumento dell'overjet. D'altra parte, l'associazione tra una ipertrofia tonsillare di grado lieve e diverse anomalie occlusali suggerisce un ruolo importante della malocclusione nell'insorgenza della respirazione orale nei bambini.

PAROLE CHIAVE: respirazione orale, malocclusione, adenoidi, tonsille, deviazione del setto nasale
Received: November 4, 2020

Accepted: April 19, 2021

Correspondence

Paola Festa

Otorhinolaryngology Unit, AORN Santobono-Pausilipon, via M. Fiore 9, 80128 Naples, Italy

E-mail: paolafesta1@gmail.com

Funding

The Authors acknowledge Ferrarelle S.p.a. for partly sustaining this research.

Conflict of interest

The Authors declare no conflict of interest.

How to cite this article: Festa P, Mansi N, Varricchio AM, et al. Association between upper airway obstruction and malocclusion in mouth-breathing children. Acta Otorhinolaryngol Ital 2021;41:436-442. https://doi. org/10.14639/0392-100X-N1225

() Società Italiana di Otorinolaringoiatria e Chirurgia Cervico-Facciale

\section{cc)(i) $\ominus$}

This is an open access article distributed in accordance with the CC-BY-NC-ND (Creative Commons Attribution-NonCommercial-NoDerivatives 4.0 International) license. The article can be used by giving appropriate credit and mentioning the license, but only for non-commercial purposes and only in the original version. For further information: https:// creativecommons.org/licenses/by-nc-nd/4.0/deed.en 


\section{Introduction}

The main causes of mouth-breathing in children are allergic rhinitis, adenoidal hypertrophy, enlarged palatal tonsils and obstructive deviation of the nasal septum ${ }^{1}$. The association between mouth-breathing and dental malocclusions has been previously reported ${ }^{2-4}$. Oral breathing is associated with a downward position of the mandible and subsequently lower position of the tongue that may result in altered craniofacial growth ${ }^{5,6}$. The reported effects on dental occlusion are increased overjet, reduced overjet, anterior or posterior crossbite, open bite and displacement of contact points ${ }^{4}$. The skeletal features associated with mouthbreathing are reduction in transversal growth of the upper arch with posterior crossbite, anterior open bite due to increase of the anterior lower facial height and development of Class II malocclusion ${ }^{5}$. On the other hand, the influence of adenoidal and tonsillar hypertrophy on dental occlusion in children is controversial ${ }^{2,7,8}$ and the association between malocclusion and nasal septum deviation has rarely been investigated ${ }^{9}$. Therefore, the aim of this study is to evaluate the association between severity of the obstruction by adenoidal and palatal tonsillar hypertrophy or the presence of nasal septum deviation and occlusal variables in mouthbreathing children to investigate the role of cause-effect between upper airways obstruction and malocclusion.

\section{Materials and methods}

This study was conducted in accordance with the principles of the Helsinki Declaration of 1975, as revised in 1983 and approval of the Ethics Committee was obtained (no. 1186_OPBG_2016).

\section{Population}

Three-hundred fifty-six patients referred to Otorhinolaryngology Unit of Bambino Gesù Children's Hospital, IRCCS (Rome, Italy) and Otorhinolaryngology Unit of Santobono-Pausilipon Children's Hospital (Naples, Italy) between July 2017 and February 2020 with the chief complaint of mouth-breathing for at least 6 months were evaluated by a multidisciplinary team comprised of ENT physicians and specialists in orthodontics in a collegiate medical examination. Exclusion criteria were: age younger than two years old, genetic syndromes, recent acute infections of the upper airways or acute otitis media in the last 10 days, previous history of orthodontic treatment or an adenoidectomy and/or tonsillectomy, acute and chronic pathologies of the lower airways, congenital malformations of the airways, chronic rhinosinusitis with nasal polyposis, dental anomalies or missing teeth in deciduous dentition.
The consent of parents and children was obtained as appropriate, after explanation of the purpose of the examination.

\section{ENT examination}

An interview was performed with the children's parents, or caregivers, to confirm the chief complaint of mouth-breathing. According to Yamaguchi et al. ${ }^{10}$, we defined a subject as a mouth-breather if the parents reported 2 or more positive items of the 3 following items during daytime: "breathes with mouth ordinarily," "mouth is open ordinarily," and "mouth is open when chewing" or 2 or more positive items among the following 3 items during nighttime: "snoring," "mouth is open during sleeping," and "mouth is dry when your child gets up". Evaluation of tonsillar hypertrophy grading was performed by an ENT specialist with more than 10 years of working experience according to Brodsky and Koch ${ }^{11}$ as follows: grade 0 , tonsils limited to the tonsillar fossa; grade 1, tonsils occupying up to $25 \%$ of the space between the anterior pillars in the oropharynx; grade 2, tonsils occupying $25-50 \%$ of the space between the anterior pillars; grade 3 , tonsils occupying $50-75 \%$ of the space between the anterior pillars; and grade 4, tonsils occupying $75-100 \%$ of the space between the anterior pillars. Nasal endoscopy was performed to evaluate adenoidal hypertrophy in 4 grades ${ }^{12}$ : grade 1 describes the adenoids occupying less then $25 \%$ of the choanal area, grade 2 adenoids occupy $25 \%$ to $50 \%$ of the choanal area, grade 3 adenoids occupy $50 \%$ to $75 \%$ of the choanal area, grade 4 adenoids occupy $75 \%$ to $100 \%$ of the choanal area. The presence of nasal septum deviation was assessed when a mucosal contact point between septal crest and inferior turbinate was seen at nasal endoscopy.

\section{Dental examination}

All children underwent a specific dental examination by two specialists in orthodontics with more than 10 years of working experience.

The following occlusal variables were evaluated:

- Primary canine relation: Class I, II, or III according to Angle classification. Due to the small number of children with an asymmetric canine relation, they were combined as Class II or Class III canine relation.

- Posterior crossbite: present, absent. A posterior crossbite was recorded if the buccal cusp of at least one upper primary or permanent molar tooth occluded lingually to the buccal cusp of the corresponding lower tooth.

- Open bite: present, absent. It was considered as present if the overlap of the lower incisors by upper incisors in the vertical plane is less than $1 \mathrm{~mm}$.

- Deep bite: present, absent. It was considered present if the overlap of the lower incisors by upper incisors in the vertical plane is more than $3 \mathrm{~mm}$. 
- Reduced overjet (OVJ): present, absent. It was considered if the distance between upper and lower incisors in the horizontal plane is less than $1 \mathrm{~mm}$.

- Increased overjet (OVJ): present, absent. It was considered if the distance between upper and lower incisors in the horizontal plane is more than $3 \mathrm{~mm}$.

The presence of malocclusion was assessed when one or more occlusal parameters were altered.

The measurements were taken manually using a calibrated calliper and the other variables were assessed by direct inspection.

\section{Statistical analysis}

The analysis was performed using the STATA software version 14.2 (StataCorp LP, College Station, TX, USA). The statistical significance was set at $P<0.05$.

All the categorical variables were summarised by absolute frequencies and percentage. The Spearman correlation coefficient (rho) was used to test the strength of association between age and adenoidal hypertrophy and between age and tonsillar grading.

Multivariable and univariate logistic regression models were developed to assess independent variables associated with occlusal findings. The independent ENT variables examined were adenoidal hypertrophy, tonsillar grading and nasal septum deviation. In multivariable analysis, the results were adjusted by age and sex.

For the purpose of statistical analysis, the dependent variable of malocclusion was both binarily grouped both analysed by multinomial logistic regression model.

\section{Results}

Two hundred and twenty-one patients (130 boys (58.8\%) and 91 girls $(41.2 \%)$, mean age $\pm \mathrm{SD}=6.2 \pm 2.5$ years $)$ were included. One-hundred and thirty-five children were excluded due to exclusion criteria.

The absolute frequencies (n) and percentage (n/N x 100\%) of ENT variables and occlusal findings is shown in Table I. The results showed a significant negative correlation between age and adenoidal hypertrophy $(\mathrm{P}<0.001$; rho $=-0.27)$ and between age and tonsillar grading $(\mathrm{P}<0.001 ;$ rho $=-0.23)$ (Tab. II).

A significant association between tonsillar grade 2 and the presence of malocclusion was found by univariate $(\mathrm{OR}=2.30, \mathrm{p}=0.05)$ and multivariable $(\mathrm{OR}=2.86$, $\mathrm{p}=0.03$ ) analyses. Furthermore, tonsillar grade 4 and the presence of malocclusion showed a significant association in multivariable analysis $(\mathrm{OR}=4.58, \mathrm{p}=0.05)$.

The results of univariate and multivariable analyses showed a significant association $(\mathrm{OR}=2.78, \mathrm{p}=0.02$ and $\mathrm{OR}=2.66$,
Table I. Prevalence of ENT and dental findings.

\begin{tabular}{|c|c|c|}
\hline Variable & $\mathrm{n}$ & $\%$ \\
\hline \multicolumn{3}{|l|}{ Sex } \\
\hline M & 130 & 58.8 \\
\hline $\mathrm{F}$ & 91 & 41.2 \\
\hline \multicolumn{3}{|c|}{ Adenoidal hypertrophy } \\
\hline 1 & 26 & 11.8 \\
\hline 2 & 79 & 35.7 \\
\hline 3 & 64 & 29.0 \\
\hline 4 & 52 & 23.5 \\
\hline \multicolumn{3}{|c|}{ Tonsillar grading } \\
\hline 1 & 45 & 20.4 \\
\hline 2 & 100 & 45.2 \\
\hline 3 & 54 & 24.4 \\
\hline 4 & 22 & 10.0 \\
\hline \multicolumn{3}{|c|}{ Nasal septum deviation } \\
\hline No & 186 & 84.2 \\
\hline Yes & 35 & 15.8 \\
\hline \multicolumn{3}{|c|}{ Presence of malocclusion } \\
\hline No & 41 & 18.6 \\
\hline Yes & 180 & 81.4 \\
\hline \multicolumn{3}{|l|}{ Class } \\
\hline I & 140 & 63.3 \\
\hline$\|$ & 67 & 30.3 \\
\hline III & 14 & 6.3 \\
\hline \multicolumn{3}{|c|}{ Posterior cross-bite } \\
\hline No & 148 & 67.0 \\
\hline Yes & 73 & 33.0 \\
\hline \multicolumn{3}{|l|}{ Open bite } \\
\hline No & 157 & 71.0 \\
\hline Yes & 64 & 29.0 \\
\hline \multicolumn{3}{|l|}{ Deep bite } \\
\hline No & 141 & 63.8 \\
\hline Yes & 80 & 36.2 \\
\hline \multicolumn{3}{|c|}{ Reduced overjet } \\
\hline No & 197 & 89.1 \\
\hline Yes & 24 & 10.8 \\
\hline \multicolumn{3}{|c|}{ Increased overjet } \\
\hline No & 151 & 68.3 \\
\hline Yes & 70 & 31.7 \\
\hline
\end{tabular}

Number of children ( $n$ ) and prevalence given in percentage ( $n / N \times 100 \%)$.

$\mathrm{p}=0.03$ ) between tonsillar grading 2 and Class II relation. Furthermore, tonsillar grade 2 showed a significant association with increased overjet in univariate $(\mathrm{OR}=5.56$, $\mathrm{p}=0.00)$ and multivariable analyses $(\mathrm{OR}=5.46, \mathrm{p}=0.00)$. 
Table II. Correlation coefficient between age and adenoidal hypertrophy and between age and tonsillar grading.

\begin{tabular}{ccccc} 
& \multicolumn{2}{c}{$\begin{array}{c}\text { Adenoidal hypertrophy } \\
(1,2,3,4)\end{array}$} & \multicolumn{2}{c}{$\begin{array}{c}\text { Tonsillar grading } \\
(1,2,3,4)\end{array}$} \\
& Rho & P & Rho & P \\
Age & -0.27 & $<0.001$ & -0.23 & $<0.001$ \\
\hline
\end{tabular}

Rho: Spearman correlation coefficient.

Moreover, tonsillar grade 4 showed a significant association with increased overjet in univariate $(\mathrm{OR}=8.00, \mathrm{p}=0.00)$ and multivariable analyses $(\mathrm{OR}=10.17, \mathrm{p}=0.00)$.

On the other hand, adenoidal hypertrophy and nasal septum deviation did not show any association with occlusal variables. No association was seen between adenoidal hypertrophy, tonsillar grading and nasal septum deviation and posterior crossbite, open bite or deep bite.

The results of univariate and multivariable analyses are presented in Tables III, IV and V.

\section{Discussion}

The objective of this study was to evaluate the association between severity of the obstruction by adenoidal and tonsillar palatal hypertrophy, the presence of nasal septum deviation and the occlusal findings in mouth-breathing children. Firstly, we found the severity of adenoidal hypertrophy and tonsillar grading decreased with age, as reported to be physiologically normal ${ }^{13}$.
In this study, the occlusal variables showed a high frequency of malocclusion in mouth-breathing children similar to data from a recent study in children with obstructive sleep apnea ${ }^{14}$. This confirms that malocclusion is more frequent in mouth-breathing children compared to nasal breathers as reported previously ${ }^{4,14}$.

No association was seen between adenoidal hypertrophy and occlusal variables in this study. This suggests that adenoidal hypertrophy does not determine an increase of malocclusion in children with mean age of 6 years. Similar results were reported by Sidlauskiene et al. ${ }^{15}$ who found no significant association between the presence of orthodontic characteristics and otorhinolaryngologic pathology (hypertrophy of adenoids or tonsils, nasal septum deviation and allergic rhinitis) in their sample and by Souki ${ }^{2}$ who reported adenoids/tonsils hyperplasia have no association with the prevalence of class II relation, anterior open bite and posterior cross-bite.

On the other hand, some cephalometric studies have suggested an association between reduced upper nasopharyngeal width and skeletal anomalies such as mandibular vertical growth evaluated in children of similar age ${ }^{16,17}$.

The absence of association between adenoidal hypertrophy and occlusal variables might also be related to the young age of patients (about 6 years old) in our study: it is conceivable that the malocclusion develops at a later age since the respiratory deficit due to adenoidal hypertrophy takes a few years before determining any dental changes. Cheng

Table III. Results of univariate and multivariable logistic regression analysis between grouped malocclusion (dependent variable) and the ENT independent variables.

\begin{tabular}{|c|c|c|c|c|c|c|c|c|c|c|c|c|}
\hline Variable & \multicolumn{4}{|c|}{ Malocclusion } & & & & & & & & \\
\hline \multicolumn{13}{|c|}{ Adenoidal hypertrophy } \\
\hline 1 & 5 & 19.2 & 21 & 80.8 & & & & & & & & \\
\hline 4 & 11 & 21.2 & 41 & 78.8 & 0.89 & 0.27 & 2.89 & 0.84 & 0.50 & 0.12 & 2.05 & 0.34 \\
\hline \multicolumn{13}{|c|}{ Tonsillar grading } \\
\hline 1 & 13 & 28.9 & 32 & 71.1 & & & & & & & & \\
\hline 2 & 15 & 15.0 & 85 & 85.0 & 2.30 & 0.99 & 5.37 & $0.05^{\star}$ & 2.86 & 1.14 & 7.17 & $0.03^{*}$ \\
\hline No & 37 & 19.9 & 149 & 80.1 & & & & & & & & \\
\hline Yes & 4 & 11.4 & 31 & 88.6 & 1.92 & 0.64 & 5.79 & 0.24 & 2.53 & 0.77 & 8.30 & 0.13 \\
\hline
\end{tabular}

statistically significant, $p$ value $\leq 0.05$. 
Table IV. Results of univariate and multivariable multinomial logistic regression analysis between classes of malocclusion (dependent variable) and the ENT independent variables.

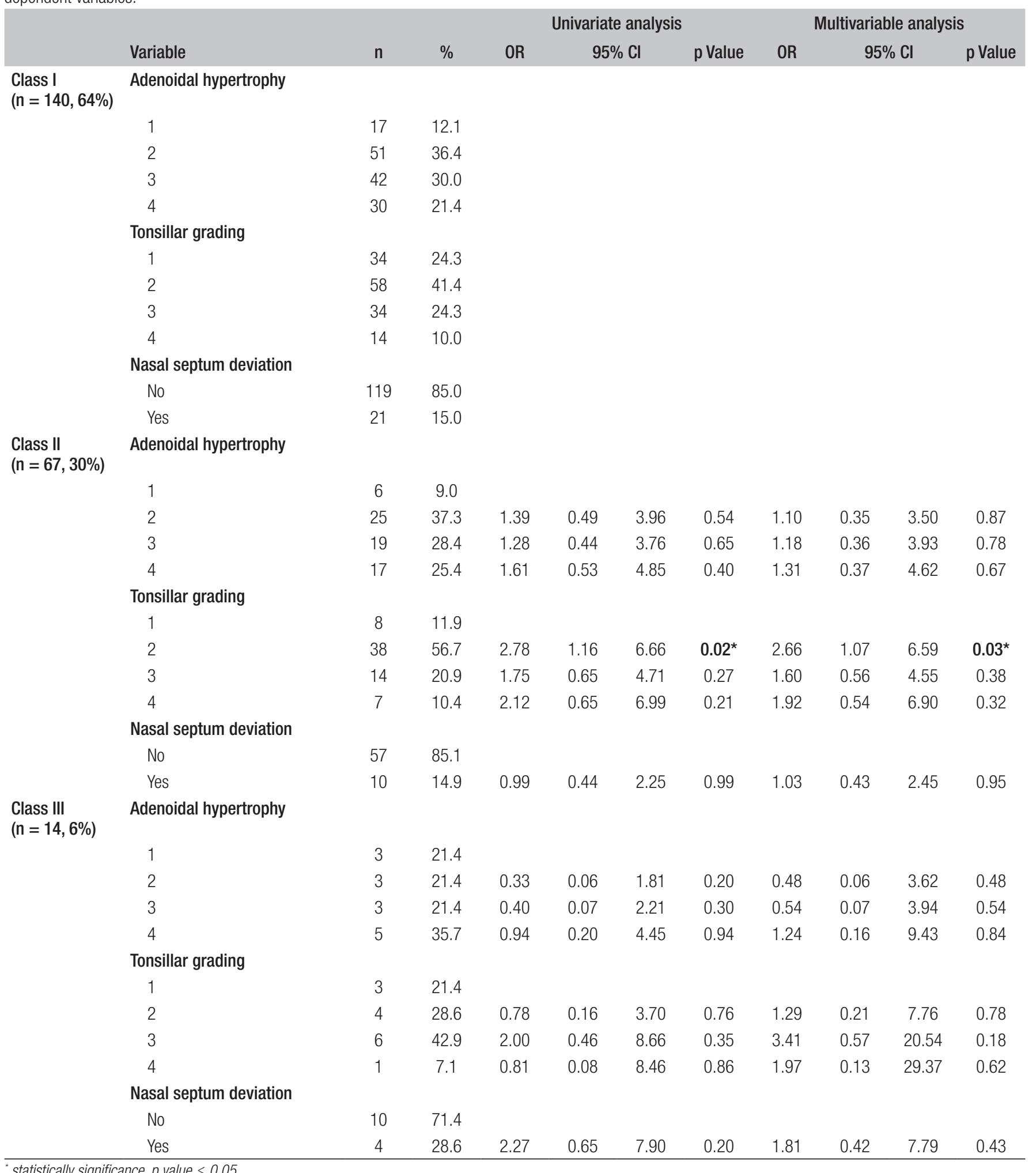


Table V. Results of univariate and multivariable logistic regression analysis between reduced or increased OVJ (dependent variable) and the ENT independent variables.

\begin{tabular}{|c|c|c|c|c|c|c|c|c|c|c|c|c|}
\hline \multirow[t]{3}{*}{ Variable } & \multicolumn{4}{|c|}{ Reduced OVJ } & & & & & & & & \\
\hline & \multicolumn{2}{|c|}{$\begin{array}{c}\mathrm{N} 0 \\
(\mathrm{n}=197,89 \%)\end{array}$} & \multicolumn{2}{|c|}{$\begin{array}{c}\text { YES } \\
(n=24,11 \%)\end{array}$} & \multicolumn{4}{|c|}{ Univariate analysis } & \multicolumn{4}{|c|}{ Multivariable analysis } \\
\hline & $\mathrm{n}$ & $\%$ & $\mathrm{n}$ & $\%$ & $\mathrm{OR}$ & \multicolumn{2}{|c|}{$95 \% \mathrm{Cl}$} & $\mathrm{p}$ Value & OR & \multicolumn{2}{|c|}{$95 \% \mathrm{Cl}$} & $p$ Value \\
\hline \multicolumn{13}{|c|}{ Adenoidal hypertrophy } \\
\hline 1 & 23 & 88.5 & 3 & 11.5 & & & & & & & & \\
\hline 2 & 72 & 91.1 & 7 & 8.9 & 0.75 & 0.18 & 3.12 & 0.69 & 0.58 & 0.11 & 2.92 & 0.51 \\
\hline 3 & 59 & 92.2 & 5 & 7.8 & 0.65 & 0.14 & 2.94 & 0.58 & 0.43 & 0.08 & 2.36 & 0.33 \\
\hline 4 & 43 & 82.7 & 9 & 17.3 & 1.60 & 0.40 & 6.52 & 0.51 & 1.11 & 0.21 & 5.94 & 0.91 \\
\hline \multicolumn{13}{|c|}{ Tonsillar grading } \\
\hline 1 & 41 & 91.1 & 4 & 8.9 & & & & & & & & \\
\hline 2 & 91 & 91.0 & 9 & 9.0 & 1.01 & 0.30 & 3.48 & 0.98 & 1.09 & 0.29 & 4.16 & 0.90 \\
\hline 3 & 45 & 83.3 & 9 & 16.7 & 2.05 & 0.59 & 7.17 & 0.26 & 2.14 & 0.53 & 8.65 & 0.28 \\
\hline 4 & 20 & 90.9 & 2 & 9.1 & 1.03 & 0.17 & 6.08 & 0.98 & 0.98 & 0.14 & 6.81 & 0.99 \\
\hline \multicolumn{13}{|c|}{ Nasal septum deviation } \\
\hline No & 166 & 89.2 & 20 & 10.8 & & & & & & & & \\
\hline Yes & 31 & 88.6 & 4 & 11.4 & 1.07 & 0.34 & 3.35 & 0.91 & 1.28 & 0.36 & 4.52 & 0.70 \\
\hline \multirow[t]{3}{*}{ Variable } & \multicolumn{4}{|c|}{ Incresed OVJ } & & & & & & & & \\
\hline & \multicolumn{2}{|c|}{$\begin{array}{c}\text { N0 } \\
(n=151,68 \%)\end{array}$} & \multicolumn{2}{|c|}{$\begin{array}{c}\text { YES } \\
(n=70,32 \%)\end{array}$} & \multicolumn{4}{|c|}{ Univariate analysis } & \multicolumn{4}{|c|}{ Multivariable analysis } \\
\hline & $n$ & $\%$ & $n$ & $\%$ & $\mathrm{OR}$ & & & $p$ Value & OR & & & $p$ Value \\
\hline \multicolumn{13}{|c|}{ Adenoidal hypertrophy } \\
\hline 1 & 21 & 80.8 & 5 & 19.2 & & & & & & & & \\
\hline 2 & 48 & 60.8 & 31 & 39.2 & 2.71 & 0.93 & 7.95 & 0.07 & 2.18 & 0.64 & 7.49 & 0.21 \\
\hline 3 & 46 & 71.9 & 18 & 28.1 & 1.64 & 0.54 & 5.02 & 0.38 & 1.62 & 0.45 & 5.90 & 0.46 \\
\hline 4 & 36 & 69.2 & 16 & 30.8 & 1.87 & 0.60 & 5.83 & 0.28 & 1.32 & 0.35 & 5.02 & 0.68 \\
\hline \multicolumn{13}{|c|}{ Tonsillar grading } \\
\hline 1 & 40 & 88.9 & 5 & 11.1 & & & & & & & & \\
\hline 2 & 59 & 59.0 & 41 & 41.0 & 5.56 & 2.02 & 15.29 & $0.00^{\star}$ & 5.46 & 1.91 & 15.65 & $0.00^{\star}$ \\
\hline 3 & 41 & 75.9 & 13 & 24.1 & 2.54 & 0.83 & 7.77 & 0.10 & 2.87 & 0.88 & 9.32 & 0.08 \\
\hline 4 & 11 & 50.0 & 11 & 50.0 & 8.00 & 2.29 & 27.93 & $0.00^{\star}$ & 10.17 & 2.59 & 39.89 & $0.00^{\star}$ \\
\hline \multicolumn{13}{|c|}{ Nasal septum deviation } \\
\hline No & 125 & 67.2 & 61 & 32.8 & & & & & & & & \\
\hline Yes & 26 & 74.3 & 9 & 25.7 & 0.71 & 0.31 & 1.61 & 0.41 & 0.81 & 0.33 & 1.97 & 0.64 \\
\hline
\end{tabular}

et al. ${ }^{18}$ noted that the younger a subject is, at the time of evaluation, the less the "adenoid" type of facial characteristics is expressed.

Furthermore, our results showed an association between tonsillar grading 2 and several orthodontic anomalies: the presence of malocclusion, Class II relation and increased overjet. These results indicate that mouth-breathing children with mild tonsillar hypertrophy often present orthodontic problems. Our hypothesis is that in patients with mild tonsillar grading the presence of breathing problems is due more to craniofacial anomalies than to the presence of upper airways obstruction. Some authors ${ }^{2}$ have highlighted the important role of heredity in mouth-breathing children as a secondary etiological factor to Class II development.

Finally, our study showed a very strong association between tonsillar Grade 4 and the presence of malocclusion $(\mathrm{OR}=4.58)$ and increased overjet $(\mathrm{OR}=10.17)$. This is interesting because it suggests that severe tonsillar hypertrophy may have an aetiologic role in the development of malocclusion. On the other hand, Diouf et al. ${ }^{8}$ showed that tonsillar Grade 4 was strongly associated with molar Class II relation and posterior crossbite with functional lateral de- 
viation of the mandible in a sample of children with mean age of about 9 years. We suppose that the difference in the mean age ( $6.2 \pm 2.5$ years) of our study compared to the higher mean age $(9.0 \pm 1.9$ years $)$ of the aforementioned study ${ }^{8}$ may explain the different results.

Therefore, this study highlights the importance of a multidisciplinary approach to children suffering from breathing disorders, such as reported in the Italian Ministry of Health guidelines on the diagnosis and management of children with obstructive sleep apnoea ${ }^{19}$.

\section{Conclusions}

The strengths of the study are: 1) few previous studies examined association between the examined variables in a large sample of children with age from 2 years; 2 ) no papers in literature reporting the association of all variables we examined in mouth-breathing children in the same study; 3) no previous studies have reported an association between nasal septum deviation and orthodontic occlusal variables.

Finally, this study showed association between severe tonsillar hypertrophy and the presence of malocclusion and increased overjet. On the other hand, mild tonsillar hypertrophy was significantly associated with the presence of malocclusion, Class II relation and increased overjet in mouthbreathers. These results suggest that malocclusion may have a dual role: it may be a determining factor in the onset of mouth-breathing in children with mild upper airway obstruction, while on the other hand it may be an effect due to severe palatal tonsil hypertrophy. Therefore, this study confirms the importance of the multidisciplinary team for diagnosis and treatment of children with breathing disorders.

\section{Acknowledgements}

The authors acknowledge all colleagues of Otorhinolaringology Unit and Dentistry Unit of Bambino Gesù Children's Hospital and AORN Santobono-Pausilipon for their contribution to this study.

\section{References}

1 Abreu RR, Rocha RL, Lamounier JA, et al. Etiology, clinical manifestations and concurrent findings in mouth-breathing children. J Pediatr 2008;84:529-535. https://doi.org/10.2223/JPED.1844

2 Souki BQ, Pimenta GB, Souki MQ, et al. Prevalence of malocclusion among mouth breathing children: do expectations meet reality? Int $\mathrm{J}$ Pediatr Otorhinolaryngol 2009;73:767-773. https://doi.org/10.1016/j. ijporl.2009.02.006
Zicari AM, Albani F, Ntrekou P, et al. Oral breathing and dental malocclusions. Eur J Paediatr Dent 2009;10:59-64.

4 Grippaudo C, Paolantonio EG, Antonini G, et al. Association between oral habits, mouth breathing and malocclusion. Acta Otorhinolaryngol Ital 2016;36:386-394. https://doi.org/10.14639/0392-100X-770

5 Chung Leng Muñoz I, Beltri Orta P. Comparison of cephalometric patterns in mouth breathing and nose breathing children. Int J Pediatr Otorhinolaryngol 2014;78:1167-1172. https://doi.org/10.1016/j. ijporl.2014.04.046

6 Al Ali A, Richmond S, Popat H, et al. The influence of snoring, mouth breathing and apnoea on facial morphology in late childhood: a three-dimensional study. BMJ Open 2015;5:e00027. https://doi. org/10.1136/bmjopen-2015-009027

7 Gois EGO, Ribeiro Junior HC, Vale MPP, et al. Influence of nonnutritive sucking habits, breathing pattern and adenoid size on the development of malocclusion. Angle Orthod 2008:78:647-654. https://doi. org/10.2319/0003-3219(2008)078[0647:IONSHB]2.0.CO;2

8 Diouf JS, Ngom PI, Sonko O, et al. Influence of tonsillar grade on the dental arch measurements. Am J Orthod Dentofacial Orthop 2015;147:214-220. https://doi.org/10.1016/j.ajodo.2014.10.028

9 D'Ascanio L, Lancione C, Pompa G, et al. Craniofacial growth in children with nasal septum deviation: a cephalometric comparative study. Int J Pediatr Otorhinolaryngol 2010;74:1180-1183. https://doi. org/10.1016/j.ijporl.2010.07.010

10 Yamaguchi H, Tada S, Nakanishi Y, et al. Association between mouthbreathing and atopic dermatitis in japanese children 2-6 years old: a population-based cross-sectional study. PLoS One 2015;10:e125916. https://doi.org/10.1371/journal.pone.0125916. eCollection 2015

11 Brodsky L, Koch RJ. Anatomic correlates of normal and diseased adenoids in children. Laryngoscope 1992;102:1268-1274. http://doi. org/10.1288/00005537-199211000-00013

12 Cassano P, Gelardi M, Cassano M, et al. Adenoid tissue rhinopharyngeal obstruction grading based on fiberendoscopic findings: a novel approach to therapeutic management. Int J Pediatr Otorhinolaryngol 2003;67:1303-1309. https://doi.org/10.1016/j.ijporl.2003.07.018

13 Mattila PS, Tarkkanen J. Age-associated changes in the cellular composition of the human adenoid. Scand J Immunol 1997;45:423-427. https://doi.org/10.1046/j.1365-3083.1997.d01-417.x

14 Galeotti A, Festa P, Viarani V, et al. Prevalence of malocclusion in children with obstructive sleep apnoea. Orthod Craniofac Res 2018;21:242-247. https://doi.org/10.1111/ocr.12242

15 Šidlauskienė M, Smailienė D, Lopatienė K, et al. Relationships between malocclusion, body posture, and nasopharyngeal pathology in pre-orthodontic children. Med Sci Monit 2015;21:1765-1773. https:// doi.org/10.12659/MSM.893395

16 Sousa JB, Anselmo-Lima WT, Valera FC, et al. Cephalometric assessment of the mandibular growth pattern in mouth-breathing children. J Pediatr Otorhinolaryngol 2005;69:311-317. https://doi.org/10.1016/j. ijporl.2004.10.010

17 Galeotti A, Festa P, Viarani V, et al. Correlation between cephalometric variables and obstructive sleep apnea severity in children. Eur J Paediatr Dent 2019;20:43-47. https://doi.org/10.23804/ejpd.2019.20.01.09

18 Cheng MC, Enlow DH, Papsidero M, et al. Developmental effects of impaired breathing in the face of the growing child. Angle Orthod 1988;58:309-320. https://doi. org/10.1043/0003-3219(1988)058<0309:DEOIBI>2.0.CO;2

19 National guidelines for prevention and dental treatment of snoring and obstructive sleep apnea in growing children. March 2016. https:// www.salute.gov.it/imgs/C_17_pubblicazioni_2484_allegato.pdf. 